This is the penultimate version of a paper published in the European Journal of Philosophy. The final publication is available online at https://doi.org/10.1111/ejop.12542. Please cite the final, published version.

\title{
Why You Cannot Make People Better by Telling them What is Good
}

\begin{abstract}
So-called optimists about moral testimony argue, against pessimists, that, ceteris paribus, we ought to accept and act in accordance with trustworthy, pure moral testimony. I argue that even if we grant this, we need to explain why moral testimony cannot make us more virtuous. I offer an explanation that appeals to the fact that we cannot share inferential abilities via testimony. This explanation is compatible with the core commitments of optimism, but it also allows us to see what is right about pessimism.
\end{abstract}

\section{Introduction}

The current debate about moral testimony and deference (henceforth "moral testimony" for brevity) was sparked, in part, by the following passage from Bernard Williams (1995, 205), cited, e.g., by Alison Hills (2009) and David Enoch (2014):

There are, notoriously, no ethical experts. [... For that] would imply, for instance, that a student who had not followed the professor's reasoning but had understood his moral conclusion might have some reason, on the strength of his professorial authority, to accept it. [...] These Platonic implications are presumably not accepted by anyone.

Pessimists about moral testimony agree with Williams that it would be intuitively problematic for the student to accept and act on a moral claim 
merely on the strength of the professor's authority (Callahan, 2018; Howell, 2014; Crisp, 2014; Hills, 2009; McGrath, 2009; Hopkins, 2007). If the student acted on the professor's testimony, her action would be less than ethically ideal, i.e., she would not act well, at least not to the highest degree. Here the claim that the action would be less than ethically ideal is a way to spell out the intuitive verdict that it would be in some way problematic for the student to accept and act on the professor's testimony. I will often use "problematic" as a placeholder to pick out the status of cases of moral testimony that is at issue in this debate.

Optimists disagree and think that "we should bite the bullet on Williams's example" (Enoch, 2014, 254). They hold that, ceteris paribus, if we receive trustworthy testimony to the effect that an action is good, we ought to accept and act in accordance with the testimony. According to optimism, if no defeating conditions obtain, we act well in such cases. Optimists have responded to examples like that of Williams by arguing that the default obligations are defeated in these examples and that this defeat can be explained in ways that are independent of the moral content of the testimony.

In this paper, I argue that it is unfortunate that the debate has focused on when moral testimony leads to obligations. A more pressing task is one for pessimists and optimist alike, namely to explain why moral testimony (by itself) cannot make us better, more virtuous, people. I shall take this explanandum for granted. It calls for an explanation because it is not obvious why there is anything missing, morally speaking, if we inform someone about all the relevant moral facts and she reliably acts in accordance with these facts and, hence, does the morally right thing. Here we have an agent that does the right thing on the basis of knowledge of the moral facts. What more could we ask for?

Pessimists sometimes acknowledge that there is something to be explained in the vicinity. Enoch, e.g., says that "forming a moral judgment 
by deference and then acting on it is much less of a moral achievement then forming the true judgment without deference, because it doesn't constitute the appropriate response to the morally relevant features of the case" (Enoch, 2014, 256). As will become clear in due course, I think that Enoch's explanation is on the right track. I aim to show, however, that once we spell out this explanation, we can do much more justice to the motivations behind pessimism than optimists seem to think. The upshot will be that if you accept the account I am offering here, you can call yourself an optimist, because you believe that we are often-perhaps even in most cases-obliged to act in accordance with trustworthy moral testimony, but your view will have a strongly pessimistic flavor.

Here is the plan: In Section 2, I recap the debate. In Section 3, I explain my novel explanation. In particular, I argue that (a) agents in cases of pure moral testimony cannot act well if and because the recipient is lacking inferential abilities, (b) this explains why moral testimony cannot make us virtuous, and (c) cases of pure moral testimony in which the agent can act well are cases in which the agent can act on the basis of good de dicto moral motivation. Section 4 considers an objection, and Section 5 takes stock.

\section{Recap of the Debate}

Optimists about moral testimony hold that, ceteris paribus, accepting moral claims on the basis of another's say-so allows the recipient to come to know the claim's content, and the recipient must, ceteris paribus, act on that knowledge (McShane, 2018; Wiland, 2017; Driver, 2015; Enoch, 2014; Lillehammer, 2014; Sliwa, 2012; Jones, 1999). Pessimists disagree and think that basing one's moral beliefs solely on the say-so of others or acting on that basis is problematic (Callahan, 2018; Howell, 2014; Crisp, 2014; Hills, 2009; McGrath, 2009; Hopkins, 2007). They often hold that it is 
problematic in ways in which deference regarding non-normative facts is not problematic. ${ }^{1}$ In this section, I will look in more detail at this dialectic.

Let's start with some terminology. What is at issue between pessimists and optimists are sometimes called cases of "pure moral testimony" or "pure moral deference" (McGrath, 2009). Cases of pure moral testimony (PMT) meet the following three conditions:

Sole-Basis The recipient's moral belief is based solely on the fact that someone else, the source, believes or asserts its content (perhaps together with the belief that the source is reliable regarding the matter, or the like). ${ }^{2}$

Moral-Content The recipient's belief has purely moral content; it is, e.g., a belief explicitly about what is good or right or what we have reason to do.

No-Understanding The mental state that the recipient acquires does not constitute moral understanding or a moral insight about why a certain action is wrong, or why something is good, or the like.

Sole Basis excludes cases where an assertion makes the agent think about the matter for herself, whereupon she comes to the same conclusion and then accepts the claim on the joint basis of deference and her own reasoning. ${ }^{3}$ The acceptance can be based on testimony, or the agent might overhear the source asserting the claim or the like.

Moral-Content requires that the testimony has explicitly moral content. This excludes cases of deference regarding non-moral information, e.g., about the consequences of certain actions. For simplicity, I ignore thick

\footnotetext{
${ }^{1}$ Sometimes this so-called Asymmetry Thesis (Groll and Decker, 2014, 54) is considered an essential part of pessimism. I am not doing so in this paper.

${ }^{2}$ The parenthetical remark is needed to stay neutral regarding the reductionism vs anti-reductionism debate in the epistemology of testimony.

${ }^{3}$ There are some complicated mixed cases, which I ignore here for simplicity (see Wiland, 2017).
} 
moral concepts here. I include, however, testimony about what we have reason to do, what is a reason for what, and the like.

No-Understanding excludes cases in which the agent, e.g., believes solely on the strength of Kant's authority that she always ought to act in accordance with the Categorical Imperative and that she ought to do $\phi$ (which we suppose to be true). By accepting these two pieces of testimony, she is also in a position to understand why she ought to $\phi$, namely because this is required by the Categorical Imperative. Similarly, we exclude cases in which the source explains to the recipient why what she says is true.

Optimism and pessimism regarding cases of pure moral testimony are broad classes of views. Robert Hopkins (2007) helpfully distinguishes two kinds of pessimism. Unavailability Pessimism says that moral deference does not make moral knowledge available. Perhaps, e.g., it is impossible to identify trustworthy sources of moral knowledge (McGrath, 2011, 2009). Unusability Pessimism says that acting on moral testimony is, by default, ethically problematic, where the precise way in which it is problematic may be different for different versions of pessimism. Unavailability Pessimism has been roundly criticized (Hills, 2009; Hopkins, 2007; Jones, 1999). In fact, Julia Driver recently wrote: "A consensus has been reached that moral knowledge can be transmitted via testimony" (Driver, 2015, 27). I will take this for granted here and, hence, focus on Unusability Pessimism. ${ }^{4}$

With the terminology thus clarified, let's have a look at the debate. Unusability Pessimists hold that in ordinary cases of PMT the recipient cannot use her knowledge to act well. They present cases in which an agent acts on pure moral testimony but fails to act well. Optimists have argued that the examples all have special features that explain why the agent doesn't act well independently of any special problem with PMT. Paulina Sliwa (2012), e.g., suggests that in some cases of PMT the agent doesn't act well because the agent is blameworthy for being ignorant of obvious

\footnotetext{
${ }^{4}$ I think that Driver's claim misses some promising lines of argument for Unavailability Pessimism, such as those pursued by Stephen Wright (2018). But I ignore that here.
} 
moral facts. Sometimes the problem arises, according to Sliwa, because the question at issue is so controversial that one should not defer to others. In some cases, the agent doesn't act well because she is blameworthy for being reluctant to make her own decisions. Etc. Sliwa thinks that these explanations have nothing to do with the moral content of the testimony and, hence, don't support pessimism.

Recently, some optimists have gone on the offensive and argued that believing and acting on moral testimony is not only unproblematic but often positively required for acting well. Enoch (2014), e.g., has argued that if we have good evidence that our source is more reliable than our own moral judgment and if being wrong will result in serious harm and injustice to a third party, then we owe it to the third party to defer to our source and to act accordingly. Eric Wiland (2017) has argued that not accepting someone's pure moral testimony often constitutes an epistemic injustice. And Paddy McShane (2018) has argued that moral deference is a valuable part of intimate relationships.

Pessimists, on the other hand, have offered several explanations that aim to bring out a common problem with (most) cases of pure moral deference. Let's look at the four most popular explanations.

Understanding Explanation: Alison Hills (2009) and Philip Nickel (2001), among others, have argued that acting with moral worth requires not just moral knowledge but moral understanding. And we cannot possess moral understanding if we defer regarding the moral question at issue. Against this explanation, Andreas Mogensen (2017) has argued that insofar as moral understanding must reach bedrock at some point, there must be an acceptance of moral claims without understanding.

Sentiment Explanation: Guy Fletcher (2016) and Laura Frances Callahan (2018), 5 among others, have argued that morally worthy action-or moral understanding, or forming moral beliefs in an acceptable way-requires

\footnotetext{
${ }^{5}$ In some cases, these explanations may not be exclusive. Callahan, e.g., presents her explanation as a variant of the Understanding Explanation.
} 
that the agent has certain sentiments, emotions, or desires, which cannot be acquired by testimony. Hence, agents in cases of PMT cannot act well because they are lacking the necessary sentiments, emotions, or desires. Some object that, contrary to what this explanation predicts, deferring to a moral guru who not only influences one's moral beliefs but also one's sentiments, emotions or desires is no less problematic than the usual cases of pure moral deference (Mogensen, 2017; Wright, 2018).

Authenticity Explanation: Mogensen holds that many cases of pure moral deference are intuitively problematic because in order to be authentic, "the beliefs which guide us through life must give expression to the true self" (Mogensen, 2017, 227). And Knut Skarsaune (2016) argues that moral deference sometimes undermines authentic interactions, and this explains what is problematic with many cases of PMT.

Character Explanation: Robert Howell (2014) has argued that virtue requires that the agent's moral knowledge is integrated into the agent's moral character. Moral beliefs based on PMT cannot be integrated into one's character in the right way. Hence, actions based on PMT cannot be manifestations of the agent's virtue. Contrary to Howell's view, Julia Driver (2015) has argued that the disposition to defer to others in moral matters can actually be a virtue.

On one possible reading, all four approaches aim to explain why it is false that, by default, recipients of PMT ought to act in accordance with their testimony. Note, however, that this is an uncharitable reading. For, under appropriate circumstances, that one ought to do something does not entail that one will act with moral worth or virtuously in doing it. For example, even if I will not act with moral worth or virtuously in acting on your testimony to the effect that I ought to treat my students with respect, I still ought to treat my students with respect. Hence, that one ought to act on one's testimonially acquired moral knowledge is compatible with (i) that one doesn't act with moral worth because one lacks moral understanding, 
(ii) that one doesn't have the sentiments necessary to act with moral worth,

(iii) that one's moral knowledge doesn't give expression to one's true self, and (iv) that one's moral knowledge is not integrated into one's character. Facts (i)-(iv) may make it impossible for the agent to act with moral worth or to act virtuously, but that doesn't imply that it is false that the agent ought to act on her testimonially acquired moral belief.

A better reading of the four explanations just rehearsed (whether or not it is what any particular author intended) is that they aim to explain why merely accepting PMT cannot make its recipient more virtuous. After all, moral understanding, appropriate sentiments, authenticity, and acting from an integrated character are, plausibly, all necessary conditions for possessing the virtues. In the remainder of this paper, I aim to show that we can squeeze a lot of juice out of this re-framing of the debate. In particular, I think many philosophers will agree that virtue cannot be acquired by merely accepting - trustworthy and true-pure moral testimony. Starting from this common ground, optimists and pessimists should be equally interested in explaining it.

\section{The Reasoning Account of PMT's Limitations}

In this section, I present my account of when and why an agent cannot act well on the basis of pure moral testimony. I will argue, first, that an agent cannot act well on the basis of PMT if and because what the agent would need in order to act well is an inferential ability and not knowledge of premises. Second, since inferential abilities cannot be shared via testimony, PMT cannot make us more virtuous. And, third, cases in which the agent can act well on the basis of PMT are cases in which de dicto moral motivation can result in acting well. Before I present my arguments, however, I want to explain and flag two presuppositions that I will take for granted.

First, I will use a very inclusive notion of practical reasoning and practical inference. Whenever someone is acting for reasons, I will say 
that the person is acting on the basis of practical reasoning or a practical inference. I will not assume that practical inferences must be intentional, or effortful, or calculative processes, or involve normative concepts.

Second, I will presuppose the following picture of acting well: To act well is to act for good reasons. As a limiting case, sometimes acting for no particular reason may count as acting for good reasons. The reasons at issue here are evidence-relative reasons, not objective reasons. Thus, you act well, e.g., in drinking the liquid in front of you, if you have good evidence that the glass in front of you contains gin and you have good reasons to drink a glass of gin, even if the glass in fact contains petrol. Given my inclusive notion of practical reasoning, to act for good reasons is to act as the result of a good piece of practical reasoning, i.e. a good practical inference. Finally, a practical inference is good if it leads from adequate starting points-e.g. justified beliefs and permissible desires of the agent-to an action (or intention) that is supported by those starting points, given the circumstances of the agent.

These two presuppositions provide a helpful way of framing our topic. Cases in which PMT is problematic are cases in which the agent is not acting well, at least not to the fullest extent. Notice that this may be the case even if the agent is doing the right thing and ought to do what she in fact does. After all, acting well may not be possible for the agent in the circumstances. So, in the problematic cases, the PMT that the agents receive does not enable them to act well. After all, we are not interested in idiosyncratic failures of agents to make adequate use of the PMT that they receive. But if the agent cannot act well, this must be either (a) because she doesn't have adequate starting points available or (b) because she cannot move from these starting points to the action or intention that they support. Hence, an account of when and why PMT doesn't enable agents to act well must say that either (a) or (b) holds in these problematic cases. 
Extant accounts of problematic PMT cases hold that the agent is lacking adequate starting points, e.g., because she lacks moral understanding, or because she lacks the right emotions or sentiments, or because the starting points don't express her true self, etc. That strategy requires either (a1) that, in problematic cases, the belief in the content of the testimony is unavailable as a premise in practical reasoning, or (a2) that, in problematic cases, good practical reasoning requires premise-attitudes that are not beliefs. (ad a1) The first option amounts to Unavailability Pessimism. (ad a2) The second option implies that rationalism about moral motivation cannot be true for any problematic PMT cases. Hence, both options lead to hefty and controversial commitments. I hypothesize that we can make progress by shifting our attention from (a) to (b). According to the account I am offering here, what is problematic about typical PMT cases arises not from (a) but from (b), i.e., the PMT does not enable the agents to move from adequate starting points to a supported action or intention.

\subsection{Lack of Inferential Abilities Prevents Acting-Well}

Given the account of acting-well that I am presupposing here, if pure moral testimony helps the agent to act well, then it either provides the agent with adequate starting points or with the ability to move from those starting points to the supported action or intention.

This is where I want to make the perhaps central observation of this paper, namely that merely accepting testimony cannot produce inferential abilities. ${ }^{6}$ Suppose, e.g., that I tell you that Fermat's Last Theorem follows from the axioms of set theory. Does that enable you to infer Fermat's Last Theorem from the axioms of set theory? Clearly not. At most, it allows you to infer Fermat's Last Theorem from (i) the axioms of set theory together with the testimonially acquired further premise that (ii) if the axioms of

\footnotetext{
${ }^{6}$ Here I am drawing heavily on recent debates about the nature of inference (Hlobil, 2019a,b), where this observation has been made and defended in more detail.
} 
set theory are true, then so is Fermat's Last Theorem. But that is a modus ponens inference (preceded by conjunction introduction), and you had the ability to infer by modus ponens before you accepted my testimony.

The same goes for practical reasoning. Suppose, e.g., that I tell you that the fact that you promised to mow my lawn is an (undefeated) reason for you to mow my lawn. In order to make it plausible that you cannot make this practical inference by yourself, let us suppose that you are a committed utilitarian and believe that you have (undefeated) reason to do something only if doing it will maximize happiness. However, let's also stipulate that you accept my testimony, perhaps because you recognize that I am more likely than you to be right about this matter. Now, does my testimony enable you to mow my lawn for the sole reason that you promised to do it, despite your belief that it doesn't maximize happiness. I think the answer is again: Clearly not. Inferential abilities cannot be shared via testimony. One way to express this is to say that you cannot see how the fact that you promised to mow my lawn gives you reason to do so, where "see" denotes whatever state of mind, if any, is required for having and exercising an inferential ability and that cannot be shared via testimony. ${ }^{7}$ In the example, you take it on trust that an appropriate support relation holds; but you cannot acquire the relevant "seeing" in this way. Just as in the theoretical

\footnotetext{
${ }^{7}$ An opponent might worry that this state of mind is just what is called "understanding" by philosophers like Hills (2009) and Nickel (2001). That may be true, but it is a substantive claim in the philosophy of reasoning. For, there is a lively debate about the so-called "Taking Condition" on inference (Boghossian, 2016, 2014; McHugh and Way, 2016; Hlobil, 2014), in which philosophers disagree about what kind of mental state, if any, inference requires. My claim is that whatever you think the necessary conditions on inference are, one of these conditions must be such that it cannot be shared via testimony. You can agree to that claim without accepting the claim that inference requires a taking that is identical to an understanding.

The different perspectives also come out in the fact that it is a substantive claim for Hills (2015) that understanding cannot (easily) be transmitted via testimony. In the debate about reasoning, however, Hlobil (2019a; 2019b) takes it to be a condition of adequacy for accounts of 'takings' that they explain why 'takings' cannot be transmitted via testimony. The upshot is that Hills claim that acting with moral worth requires moral understanding is controversial. By contrast, my claim that inferential abilities cannot be shared via testimony should not be controversial.
} 
case, a mere belief that an appropriate support relation holds does not enable you to make the inference.

In parallel to the modus ponens inference to Fermat's Last Theorem, we may suppose that you can mow my lawn for the reason that (i) you promised to do it and (ii) this promise gives you an (undefeated) reason to mow my lawn. Notice, however, that my testimony said that (i) is a good reason to mow my lawn, whereas you are now mowing my lawn for the reason that (i) \& (ii). If, and insofar as, it is possible that (i) is a good reason to mow my lawn but (i) \& (ii) isn't, you may not act well if you use my testimony as a further premise, by adding (ii) to the premises of your practical inference.

At this point, an opponent might raise the following worry: ${ }^{8}$ Even if you cannot reason from just (i) to the action of mowing the lawn, you can still reason to that conclusion using the testimony as a guide or perhaps as one of the premises by reasoning from (i) \& (ii). The original premise (i), "I promised to mow the lawn", is still among your premises. So, if you act on that inference, one reason for which you are mowing the lawn is that you promised to do it. By our stipulations about the case, this means that you are mowing the lawn for at least one good reason. But I said that to act well is to act for good reasons. So how can it be that you are not acting well in this case?

My response is that in order to act well, it doesn't suffice that a good reason is among a collection of reasons that jointly constitute the premises from which you act. Rather, in order to act for good reasons, you must act as the result of a good practical inference. And that there is a good practical inference that leads from a subset of your premises to your conclusion does not guarantee that your (larger) actual set of premises also supports your conclusion. Consider, e.g., the following practical inference: “(i) I promised $\mathrm{NN}$ to mow the lawn. And (iii) if I keep that promise, I can put pressure on

\footnotetext{
${ }^{8}$ Thanks to an anonymous referee for pressing me on this point.
} 
NN to help me rob the local grocery store. So I will mow the lawn." One of the premises is that you promised to mow the lawn, and the conclusion is the action or intention to mow the lawn. In acting on that inference, however, you don't act well. Hence, the fact that (i) is one of your premises and that you mow the lawn as a result of the inference does not guarantee that you act well. Therefore, there is room for the position that just as the inference from (i) \& (iii) to mowing the lawn is not a good inference, so the inference from (i) \& (ii) to mowing the lawn is not a good inference. And this is what I maintain is going on in this case.

The opponent may object by holding that the inference from (i) \& (ii) to mowing the lawn is in fact a good practical inference. That does not undermine my account, as long as the opponent also holds that in this case, PMT to the effect that you should keep your promises enables you to act well and, hence, that this case of PMT is not intuitively problematic. I will return to this issue below.

The observation that inferential abilities cannot be shared via testimony gives us a way to explain why some cases of PMT are intuitively problematic while also agreeing with the optimist that beliefs acquired on the basis of good testimony can always be used as premises in practical reasoning (while also staying neutral on rationalism about moral motivation). If our case is such that the agent has adequate starting points available, or that testimony could make such starting points available, but, for any such adequate starting points, the agent lacks the ability to move from these starting points to the action or intention they support, then we have a case where PMT cannot help the agent to act well. In such cases, acting on the basis of PMT will be problematic because the agent cannot act well, at least not to the fullest extent. This explanation of what goes wrong in many cases of PMT doesn't put any restrictions on the ability of PMT to provide us with knowledge or on our ability or duty to act on such 
knowledge. Thus, the explanation is compatible with the optimist's claim that we usually ought to accept and act in accordance with PMT.

To sum up, I have argued that PMT is problematic if and because the agent is lacking an inferential ability and not knowledge of premises. Perhaps there are also other cases in which PMT is problematic. However, cases of problematic PMT that are covered by my account are compatible with the core commitments of optimists. As will become clear over the remainder of this paper, my account nevertheless captures a lot of the spirit of pessimism.

\subsection{Why PMT Cannot Make Us Virtuous}

In this subsection, I show how the reasoning account of PMT's limits, which I presented in the previous subsection, explains why PMT cannot make the recipient more virtuous. The core idea is that virtues require certain abilities to reason practically. As we have seen, however, inferential abilities cannot be shared via testimony.

Some potential misunderstandings must be forestalled immediately. I am not saying that pure moral testimony cannot be an important part of moral education that results in virtuous people, or that forming a habit by acting on the basis of moral testimony is never necessary for acquiring a particular virtue. In fact, it seems to me that Aristotle is right in holding that habituation is a crucial part of a good ethical upbringing. And accepting pure moral testimony is most probably an important part of such habituation. In this limited sense, moral testimony can make people more virtuous. However, in moral upbringing moral testimony is merely a part of a process of habituation that leads to practical wisdom (phronesis), which includes the ability to make certain practical inferences. This is compatible with the claim that merely reliably accepting and acting on trustworthy moral testimony does not make a person more virtuous. It is this last fact that is the explanandum that I take for granted in this paper. The fact calls 
for an explanation because if virtues are, say, reliable dispositions to do the right thing on the basis of moral knowledge, then it is unclear why merely accepting and acting on moral testimony should not make you more virtuous. We need a better conception of the virtues and their connection to acting well and testimony.

I will follow Aristotle who says that virtues are dispositions to choose well (EN 1106b36). Different virtues concern choices in difference spheres of human experience, to use Nussbaum's $(1987,35)$ apt phrase. Courage, e.g., concerns choices that are made in the face of danger. Furthermore, Aristotle tells us that a choice is the result of practical reasoning or deliberation (EN 1113a4). Since one chooses well just in case one chooses as the result of a good piece of practical reasoning, the possession of a virtue requires that one possesses the abilities to engage in the corresponding pieces of practical reasoning, at least sufficiently often to count as having a disposition to choose well in the relevant sphere of human experience.

Now, we have seen that the ability to make certain practical inferences cannot be shared via testimony. Hence, testimony-including pure moral testimony-cannot provide one necessary aspect of virtue, namely the ability to make practical inferences that is required for a particular virtue. Moreover, I have argued above that in certain cases of problematic PMT, what is lacking in a person who receives PMT are precisely such inferential abilities. Thus, such cases of problematic PMT are cases in which the agent fails to meet a necessary condition for being virtuous, and the moral testimony she receives cannot help with that problem.

What I said so far doesn't show that PMT can never make its recipient more virtuous. It merely shows that there is one necessary condition for possessing virtues that merely accepting and acting on PMT cannot provide. An opponent may hold that there are jointly sufficient conditions for being virtuous, or for possessing a particular virtue, that accepting PMT may provide. Plausible candidates for such jointly sufficient conditions are 
dispositions to feel certain emotions in certain circumstances, dispositions to perceive morally relevant facts easily and accurately, dispositions to desire only things that are desirable and to do so with the right degree, etc. An opponent might hold that PMT can make us virtuous by enabling us to meet one of these conditions, when we already meet the others.

My response comes in two stages. First, I doubt that any of the plausible conditions just listed can be met by merely accepting testimony. Dispositions to feel emotions, to have perceptions and the like are not the kinds of things that can be acquired by merely accepting testimony. The second stage of my response is more conciliatory. I don't insist that merely accepting and acting on PMT can never make us virtuous. Rather, I take it for granted as my explanandum. My account offers an explanation, and it does that even if it allows for cases in which merely accepting and acting on PMT makes someone more virtuous. For such cases are plausibly rare, if they occur at all. They are cases in which knowledge or justified belief that can be shared via testimony is one of a set of jointly sufficient conditions for possessing a virtue, and the agent already meets the other conditions.

Another opponent might worry that testimony is on a par with other ways of acquiring moral knowledge with respect to becoming virtuous. If I reason carefully for myself to a conclusion about what I ought to do and I then do it in a one off way-deviating from my usual vicious ways - this doesn't make me any more virtuous. If I instill the habit of doing the act in me, along with the right emotions, etc., then I will become more virtuous. Hence, moral testimony seems to be no better and no worse than any other way of gaining moral knowledge.

To see that this objection fails, notice that, on my view, virtue doesn't require that you reason correctly to a belief about what you ought to do and act on that conclusion. Rather, virtue requires that you reason practically to a permissible action, from premises that are sufficient reasons for that action. Every time you reason well in this way will contribute to 
you becoming virtuous. Any way of knowing what you ought to do that doesn't come with a corresponding ability for good practical reasoning will not make you more virtuous. Learning what you ought to do via testimony doesn't come with a corresponding ability for good practical reasoning. ${ }^{9}$ Hence, it doesn't make you more virtuous. That is the fact that I set out to explain. Other ways of learning what you ought to do may also fit that description, including some cases of theoretical reasoning about what you ought to do. For these ways of knowing what you ought to do, we also need an explanation of why they don't make you virtuous. And my account obviously provides one. What would be problematic was if my account implies that ways of knowing what you ought to do that clearly make you more virtuous don't make you more virtuous. But, as far as I can see, there aren't any such ways of knowing what you ought to do.

\subsection{Unproblematic PMT Cases are Cases of Good De Dicto Moral Motivation}

Cases of de dicto moral motivation are cases where an agent does something for the reason that-and under the description that-it is the right thing to do, that it is good, that she has decisive reasons for doing it, or the like. There is an ongoing debate about when (if ever) agents who act on de dicto moral motivations are acting well (King, 2020b,a; Aboodi, 2017, 2015; Arpaly, 2015, 2002; Weatherson, 2014; Carbonell, 2013; Markovits, 2010; Smith, 1994). While I will stay neutral regarding this question, my account allows us to see how this question bears on debates about moral testimony. More precisely, I will argue in this subsection that cases in which PMT is not problematic are cases in which one can act well by acting on de dicto moral motivation.

\footnotetext{
${ }^{9}$ As I said at the start of this subsection, this claim must be understood as allowing for exceptions that arise from the role that moral testimony may play in habituation and ethical upbringing. I henceforth leave this qualification implicit.
} 
Recall that, according to my inclusive use of the term, acting for certain reasons is acting as the result of a practical inference in which these reasons serve as premises. Moreover, you act well just in case you act for good reasons, i.e. as the result of a good practical inference. It follows that if you can act well by acting on de dicto moral motivation, then you can act well as the result of a practical inference with de dicto moral claims as premises, and vice versa.

Now, if you accept pure moral testimony and treat it as a reason on which you act, then you act on the basis of a de dicto moral motivation. For, what you learn from pure moral testimony is that doing such-and-such would be the right thing to do, or good, or that you have decisive reasons for doing it, etc. And treating any such fact as a reason for doing such-andsuch and acting on it is to do such-and-such on the basis of a de dicto moral motivation.

According to the account of problematic PMT cases offered above, unproblematic cases of PMT are cases in which the agent can make a good practical inference in which what she learns from pure moral testimony figures as a premise. In such cases, the agent can act well on the basis of the testimony that she receives. Since these are cases of de dicto moral motivation, unproblematic cases of PMT are cases where one can act well on the basis of de dicto moral motivation.

Exploiting this relation, we can see that if we suppose that de dicto moral motivation can usually lead to acting well, then my account will predict few cases of problematic PMT. If, however, we suppose that de dicto moral motivation only rarely allows for acting well, then my account will predict that there are many cases of problematic PMT. If you think, e.g., that it is virtually always good practical reasoning to reason from " $P$ and $P$ is a decisive reason for me to $\phi^{\prime \prime}$ to doing $\phi$ and that virtually everyone has the ability to make inferences of this form, then (according to your view) receiving pure moral testimony to the effect that " $P$ is a decisive reason for 
me to $\phi^{\prime \prime}$ will virtually always allow the agent to act well. If, on the other hand, you believe that, in some cases, acting on a reason like " $P$ and $P$ is a decisive reason for me to $\phi$ " is to act on "one thought too many" (Williams, 1981), then (according to your view) it will be considerably more difficult for PMT to enable the agent to act well.

To illustrate, let's return to the case above, where you mow my lawn for the reason that (i) you promised to do it and (ii) this promise gives you an (undefeated) reason to mow my lawn. If you think that (ii) is one thought too many, then you should think (according to my account) that PMT that supplies the agent with knowledge of (ii) cannot help the agent to act well. Hence, other things equal, you should predict that such a case of PMT will be intuitively problematic. If, however, you think that acting on (i) \& (ii) is not to have one thought to many and that acting on de dicto moral motivation allows the agent to act well in this case, then you should think that PMT can enable the agent to act well and that, other things being equal, the case will not be intuitively problematic.

It seems to me that this is the correct result. For what it is worth, I cannot find a case of unproblematic PMT where I think that the corresponding case of de dicto moral motivation is not okay. Conversely, if I start with a case in which I judge de dicto moral motivation to be okay and I don't introduce any additional complicating factors (such as those typically appealed to in explanations of problematic PMT), then I find that I judge the corresponding case of PMT to be unproblematic. I will leave it as an exercise to the reader to test her favorite cases of de dicto moral motivation and PMT. Should anyone find a counterexample, I will welcome it not only as falsifying the account I put forward here but also as providing new insight into the relation between PMT and de dicto moral motivation. 


\section{An Objection}

In this section, I want to address a potential objection, namely that my account is vulnerable to the arguments that Enoch (2014), Wiland (2017), and McShane (2018) have leveled against pessimism. They argue that we are sometimes positively required to act on testimonially acquired moral beliefs. How can my account explain that?

My response is that, according to my view, the cases that Enoch, Wiland, and McShane describe are all cases in which de dicto moral motivation allows the agent to act well. In other words, in these cases, there is a good practical inference available to the agents in which the testimonially acquired moral belief figures as a premise. If there isn't any other good practical inference available to the agent, then the only way for the agent to act well is to act on the basis of their testimonially acquired moral belief.

Why certain practical inferences are good and others aren't is an interesting but, unfortunately, very large question. Fortunately, the response I offered in the previous paragraph doesn't commit me to any particular answer to this question. It merely commits me to the claim that you will find Enoch's, Wiland's, and McShane's criticism convincing only to the extend that you think that the kind of good practical inference that I just described is available to the agents in their cases. If you think so, you will find my response also convincing. If you don't think there is such an inference available to the agents, then you shouldn't find the criticism convincing in the first place.

\section{Conclusion}

Let's take stock. I have presented a new account of when and why cases of pure moral testimony are intuitively problematic. My account is compatible with the core commitments of optimism about moral testimony, namely the claim that moral testimony makes moral knowledge available and the claim 
that recipients of moral testimony sometimes ought to act on such knowledge. Rather than denying one of these two claims, my account locates the limitation of moral testimony in the fact that inferential abilities cannot be passed on via testimony. This is a general fact that is true of theoretical and practical reasoning alike. In the practical realm, however, we can use it to explain why certain cases of moral testimony are problematic, why moral testimony cannot make us more virtuous, and why unproblematic cases of moral testimony are cases in which one can act well on the basis of de dicto moral motivation.

The account I presented here is compatible with many extant accounts of what is problematic about pure moral testimony. Perhaps different cases are problematic for different reasons. It is a distinctive virtue of my account, however, that it allows us to argue for stronger or weaker versions of optimism or pessimism on the basis of claims about when and why de dicto moral motivations can lead to acting well. If such claims about de dicto moral motivation can be established on independent grounds, this opens up new avenues in the debate about moral testimony.

\section{References}

Aboodi, R. (2015). The wrong time to aim at what's right: When is de dicto moral motivation less virtuous? Proceedings of the Aristotelian Society, 115(3):307-314.

Aboodi, R. (2017). One thought too few: Where de dicto moral motivation is necessary. Ethical Theory and Moral Practice, 20(2):223-237.

Aristotle (2014). Complete Works of Aristotle: Volume 2 (revised Oxford translation, edited by J. Barnes). Princeton University Press, Princeton.

Arpaly, N. (2002). Moral worth. Journal of Philosophy, 99(5):223-245.

Arpaly, N. (2015). Huckleberry Finn revisited: Inverse akrasia and moral ignorance. In Mckenna, R. C. M. and Smith, A. M., editors, The Nature of Moral Responsibility, pages 141-156. Oxford University Press, New York.

Boghossian, P. (2016). Rationality, reasoning and rules: Reflections on Broome's Rationality Through Reasoning. Philosophical Studies, 173(12):3385-3397.

Boghossian, P. A. (2014). What is inference? Philosophical Studies, 169(1):1-18. 
Callahan, L. F. (2018). Moral testimony: A re-conceived understanding explanation. Philosophical Quarterly, 68(272):437-459.

Carbonell, V. (2013). De dicto desires and morality as fetish. Philosophical Studies, 163(2):459-477.

Crisp, R. (2014). Moral testimony pessimism: A defence. Aristotelian Society Supplementary Volume, 88(1):129-143.

Driver, J. (2015). Virtue and moral deference. Etica \& Politica / Ethics \& Politics, XVII(2):27-40.

Enoch, D. (2014). A defense of moral deference. Journal of Philosophy, 111(5):229258.

Fletcher, G. (2016). Moral testimony: Once more with feeling. In Shafer-Landau, R., editor, Oxford Studies in Metaethics: volume 11, pages 45-73. Oxford University Press, Oxford.

Groll, D. and Decker, J. (2014). Moral testimony: One of these things is just like the others. Analytic Philosophy, 55(1):54-74.

Hills, A. (2009). Moral testimony and moral epistemology. Ethics, 120(1):94-127.

Hills, A. (2015). Understanding why. Noûs, 50(4):661-688.

Hlobil, U. (2014). Against Boghossian, Wright and Broome on inference. Philosophical Studies, 167(2):419-429.

Hlobil, U. (2019a). Inferring by attaching force. Australasian Journal of Philosophy, 97(4):701-714.

Hlobil, U. (2019b). We cannot infer by accepting testimony. Philosophical Studies, online first:1-10.

Hopkins, R. (2007). What is wrong with moral testimony? Philosophy and Phenomenological Research, 74(3):611-634.

Howell, R. J. (2014). Google morals, virtue, and the asymmetry of deference. Noûs, 48(3):389-415.

Jones, K. (1999). Second-hand moral knowledge. Journal of Philosophy, 96(2):55-78.

King, Z. J. (2020a). Accidentally doing the right thing. Philosophy and Phenomenological Research, doi: 10.1111/phpr.12535.

King, Z. J. (2020b). Praiseworthy motivations. Noûs, doi: 10.1111/nous.12276.

Lillehammer, H. (2014). Moral testimony, moral virtue, and the value of autonomy. Aristotelian Society Supplementary Volume, 88(1):111-127.

Markovits, J. (2010). Acting for the right reasons. Philosophical Review, 119(2):201242.

McGrath, S. (2009). The puzzle of pure moral deference. Philosophical Perspectives, 23(1):321-344.

McGrath, S. (2011). Skepticism about moral expertise as a puzzle for moral realism. Journal of Philosophy, 108(3):111-137.

McHugh, C. and Way, J. (2016). Against the taking condition. Philosophical Issues, 26(1):314-331.

McShane, P. (2018). The non-remedial value of dependence on moral testimony. Philosophical Studies, 175(3):629-647. 
Mogensen, A. L. (2017). Moral testimony pessimism and the uncertain value of authenticity. Philosophy and Phenomenological Research, 95(2):261-284.

Nickel, P. (2001). Moral testimony and its authority. Ethical Theory and Moral Practice, 4(3):253-266.

Nussbaum, M. C. (1987). Non-relative virtues: An aristotelian approach. Midwest Studies in Philosophy, 13(1):32-53.

Skarsaune, K. O. (2016). Moral deference and authentic interaction. Journal of Philosophy, 113(7):346-357.

Sliwa, P. (2012). In defense of moral testimony. Philosophical Studies, 158(2):175-195. Smith, M. (1994). The moral problem. Blackwell, Oxford.

Weatherson, B. (2014). Running risks morally. Philosophical Studies, 167(1):141-163. Wiland, E. (2017). Moral testimony: Going on the offensive. Oxford Studies in Metaethics, 12:51-75.

Williams, B. (1981). Persons, character, and morality. In Rachels, J., editor, Moral Luck: Philosophical Papers 1973-1980. Cambridge University Press, Cambridge.

Williams, B. (1995). Making Sense of Humanity. Cambridge University Press, Cambridge.

Wright, S. (2018). Trust in the normative domain. International Journal of Philosophical Studies, 26(2):187-204. 